\title{
Reward Models for Active Language Learning in 3D Virtual Worlds
}

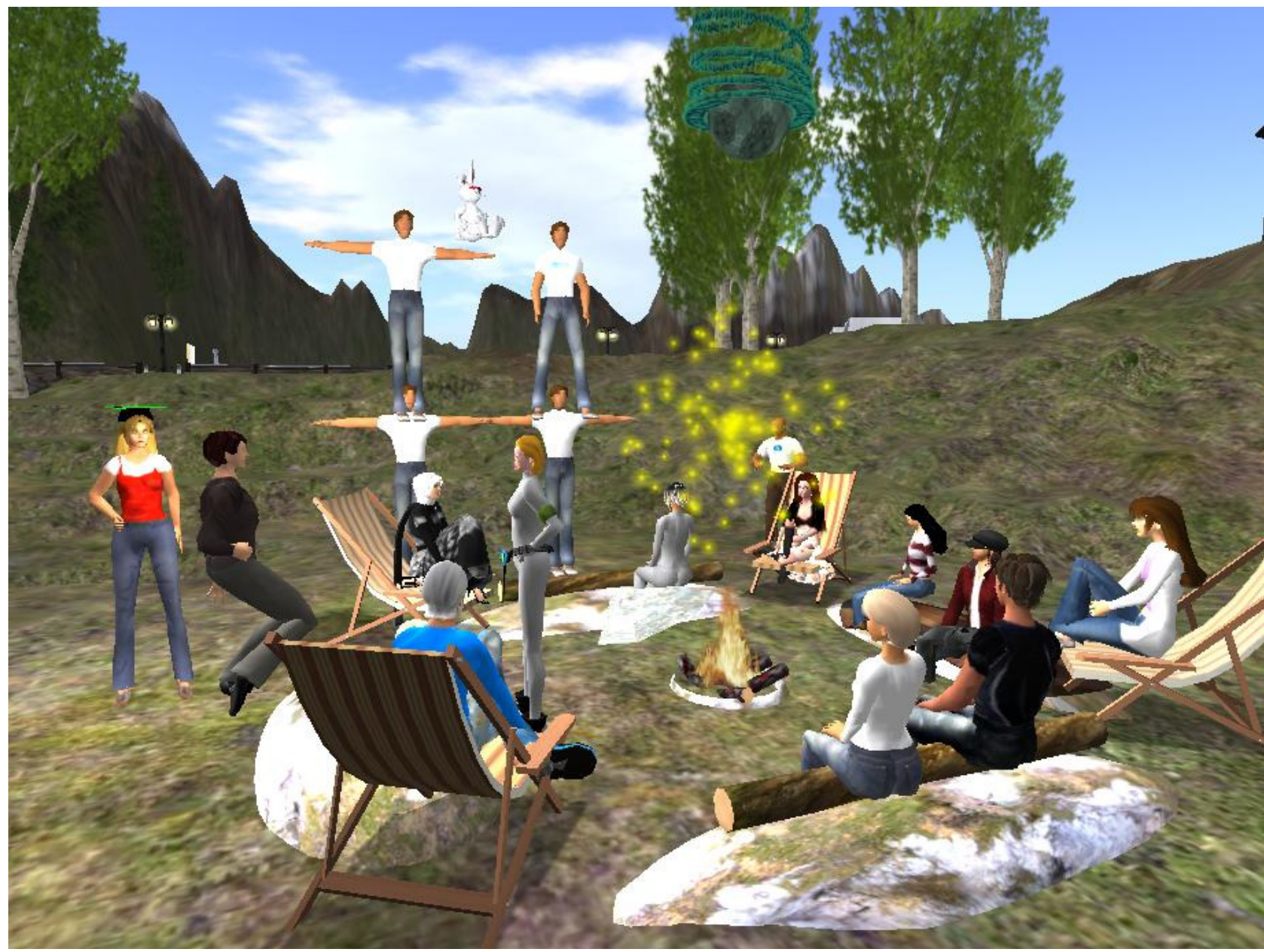

Judith Molka-Danielsen Molde University College, Norway j.molkadanielsen@himolde.no

Luisa Panichi

Università di Pisa, Italy

Mats Deutschmann

Umeå University , Sweden

\section{Presented at:}




\section{Motivation}

- A main distinction for reward models is made between

- intrinsic (internal- "I do this because I want to") and

- extrinsic (external - "I do this because someone wants me to do it") motivation [7].

- Another distinction is that between instrumental and integrative motivation [6].

- Instrumental motivation involves the learning of a language for specific goals/rewards, for example getting a good grade, being able to apply for a certain job, qualifying you for a particular university program etc.

- Integrative motivation, on the other hand, the motivation lies in gaining access to a community or a culture through a language. 


\section{What is relevant reward?}

One dilemma in language education is actually providing relevant rewards.

- Language is the key to communication and access to a new culture. Without language we are isolated.

- The reward models operating in the classroom, rarely confront students with authentic communicative scenarios.

- They might get $x$ out of ten in a vocabulary test, and of course this can be reward/punishment in itself, but in real life knowing or not knowing the word for 'water' might mean the difference between going thirsty or not. We must account for the cultural dimension in language learning models.
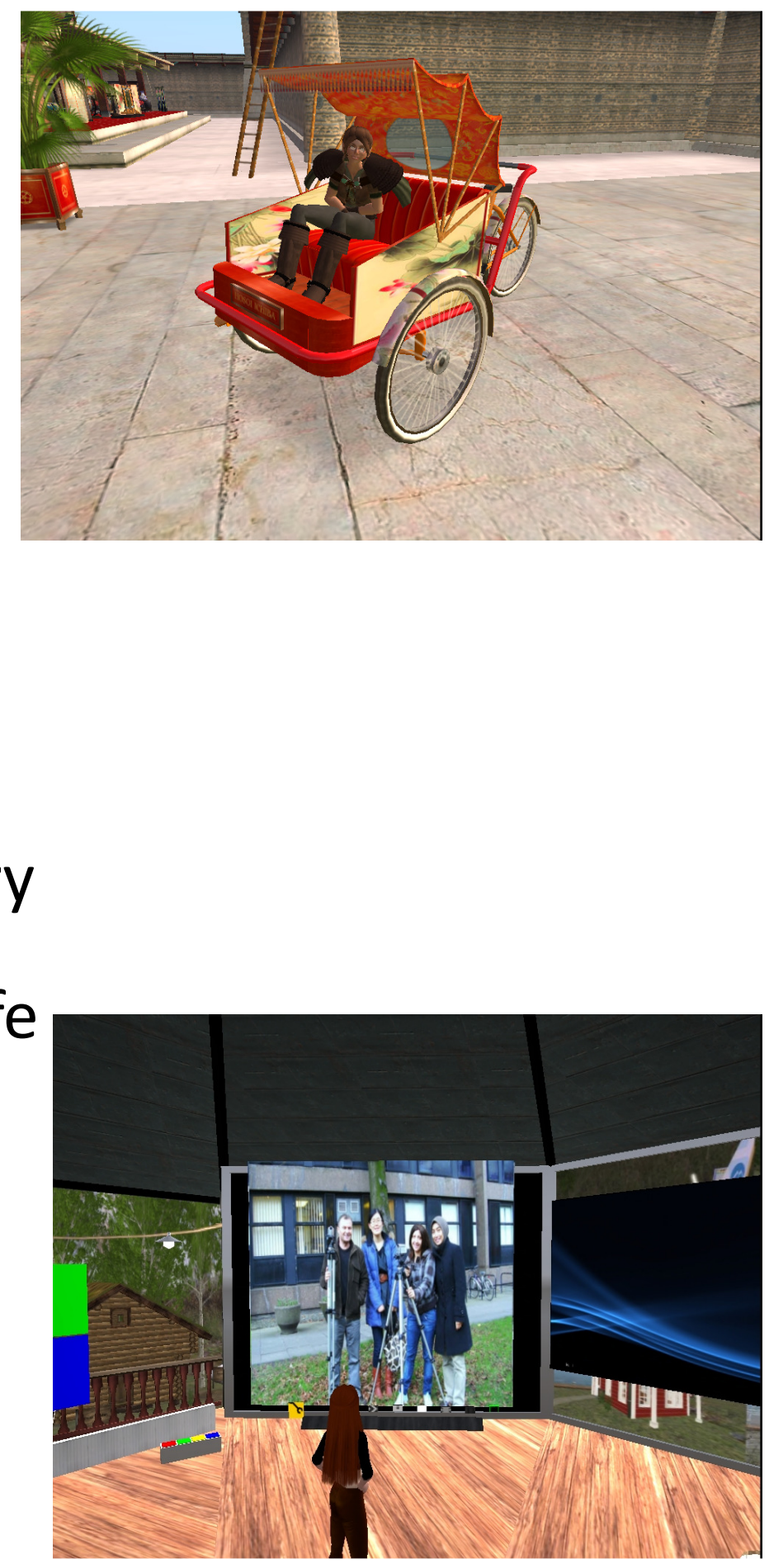
Mobile applications for language learning: can be helpful for those who did not have time to learn before the trip!

I would like..
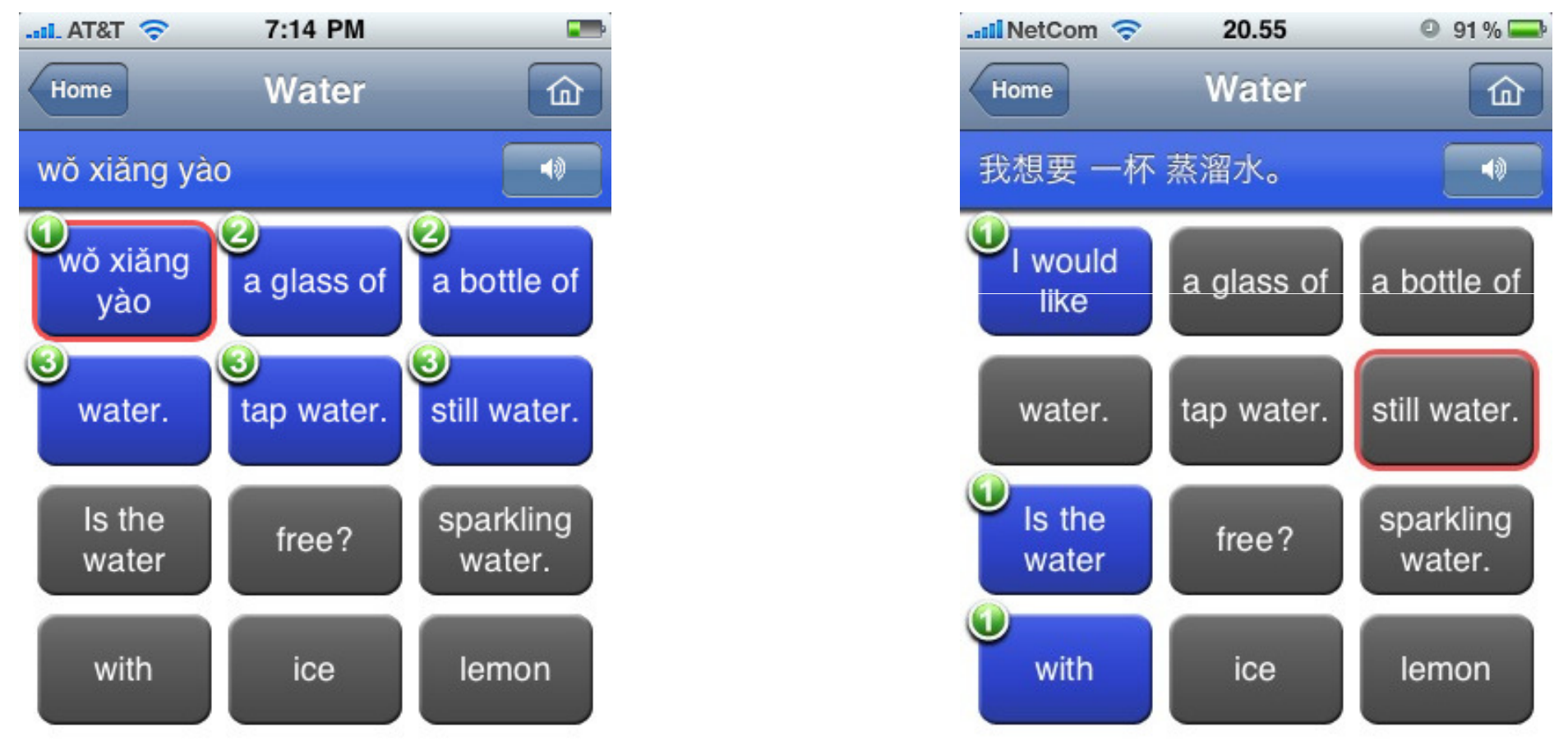

(Screenshots from Odyssey Translator)

But they are not a substitute for learning in a social-cultural context. 


\section{What are vitural worlds and why use them for language learning?}

\section{What are virtual worlds?}

- Virtual worlds are 3D multi-user online computer simulated environments.

- A user can be represented as an avatar, moving around and sharing world content with other avatars.

- Second Life ${ }^{\mathrm{TM}}$ is one example of a virutal world where users can experience communication, networking and shared activities, some that are not possible in the real world, such as flying (without an aircraft).
Why use them for language learning?

- In virtual worlds, re-conceptualization of self is possible (self-determination).

- Tasks can be designed in such a way that they realistically simulate real life communicative scenarios in the target language.

- Completion of a communicative task is a reward in itself. Being understood and authentic communicative exchanges are thus highly rewarding (thus motivating.) 


\section{Four Components of a successful computer game}

- Meaningful challenge - has attainable goals within the game structure and the perception of the players. The goals have value, and conflicts are components that make the goal a challenge.

- Self-consistent setting - is a co-constructed alternative reality that is made by the game structure (rules, stories or thematic representations, visual aids) and the imagination of the participants [14]. The thematic representations are built on narrative genres that are often based on general cultural knowledge.

- Player presence - is the emotional investment of the participant in the game and this creates a sense of immersion. As pointed out by [13, p.86], "the game token is no longer a piece of plastic, the game token becomes "you".

- Embedded helps - are information or feedback seen as part of the selfconsistent setting; in other words, it may be part of the narrative. 


\section{Csikszentmihalyi - flow theory explains how persons are motivated to learn in games}

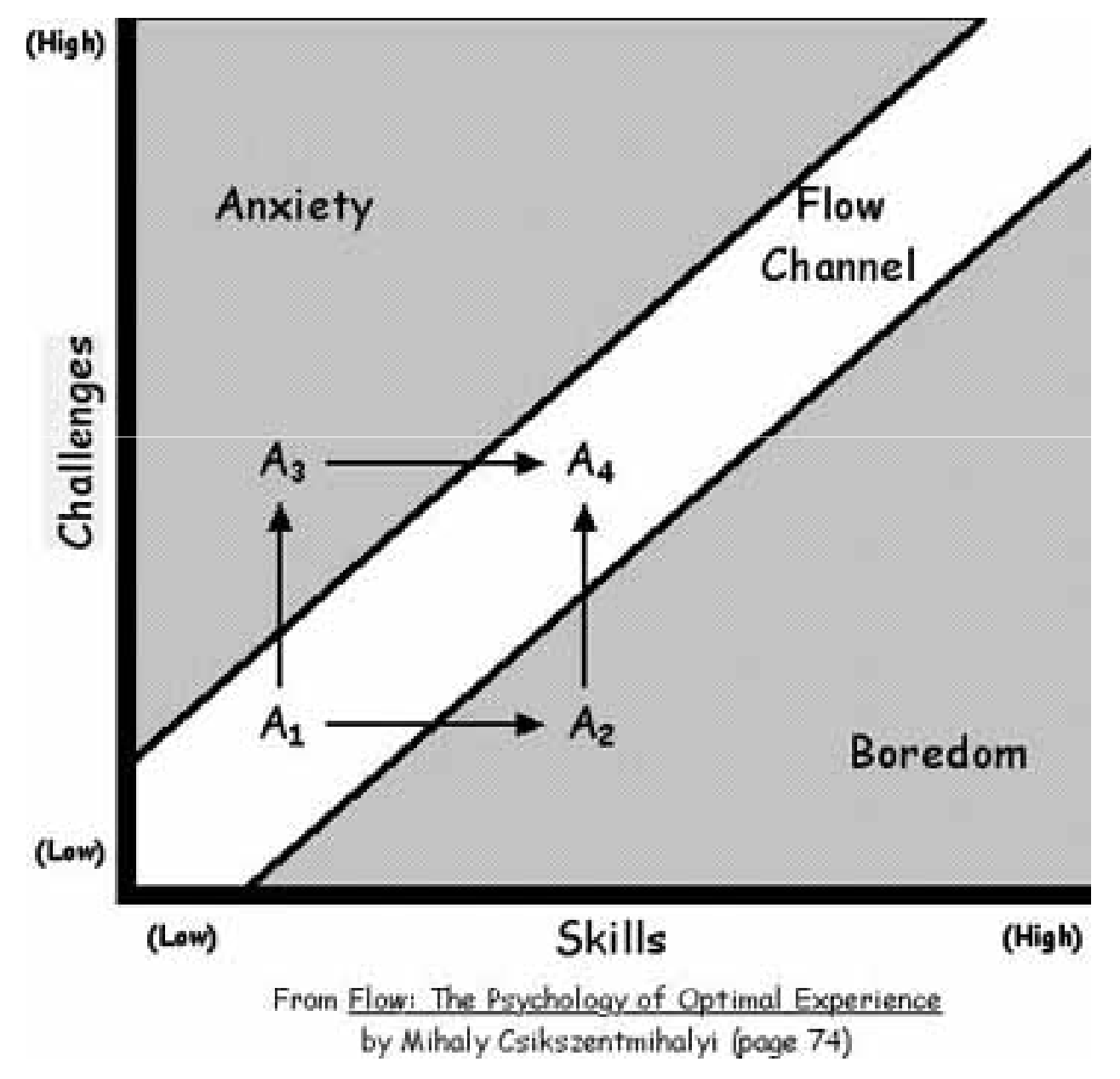




\section{Four types of rewards for computer role-playing games}

- rewards of glory (have no impact on the game but give the player satisfaction and pleasure)

- sustenance (allow accumulation of inventory, such as magic swords)

- access (rights of access to new portions of the game)

- facility (new abilities) 


\section{Business English Course offered in Second Life ${ }^{\mathrm{TM}}$}

Main objectives were to provide learners with:

(1) business language practice and language knowledge appropriate for their learning level

(2) the necessary technical knowledge of SL to make this language learning experience effective and meaningful

(3) create a viable model of how SL can be used for teaching a business language course and an awareness of SL potential for online language education in general within the language education community

(4) show the benefit of using SL for teaching a business language course as opposed to other platforms for online language learning

- Course was designed with intermediate business language learners. students who need to develop their language knowledge and skills for business.

- The course was divided into 6 lessons or meetings in which the course instructor and course participants come together at the same time and place in SL. 4 groups of 3-4 students participated. 


\section{General layout of the virtual sim AVALON Learning}

- The meeting place for the Business English course is in a structure called the "business barn" (BB), located between the village and the harbor areas on AVALON.

- The BB contains "office space" for posting information and for holding meetings. It also has a meeting location with chairs for an audience and a media screen for presentation of materials.

- The BB can be used for activities such as "dragon's den" where students can present business ideas before a panel of judges.

- The students that are successful in the "dragon's den" activity will be given

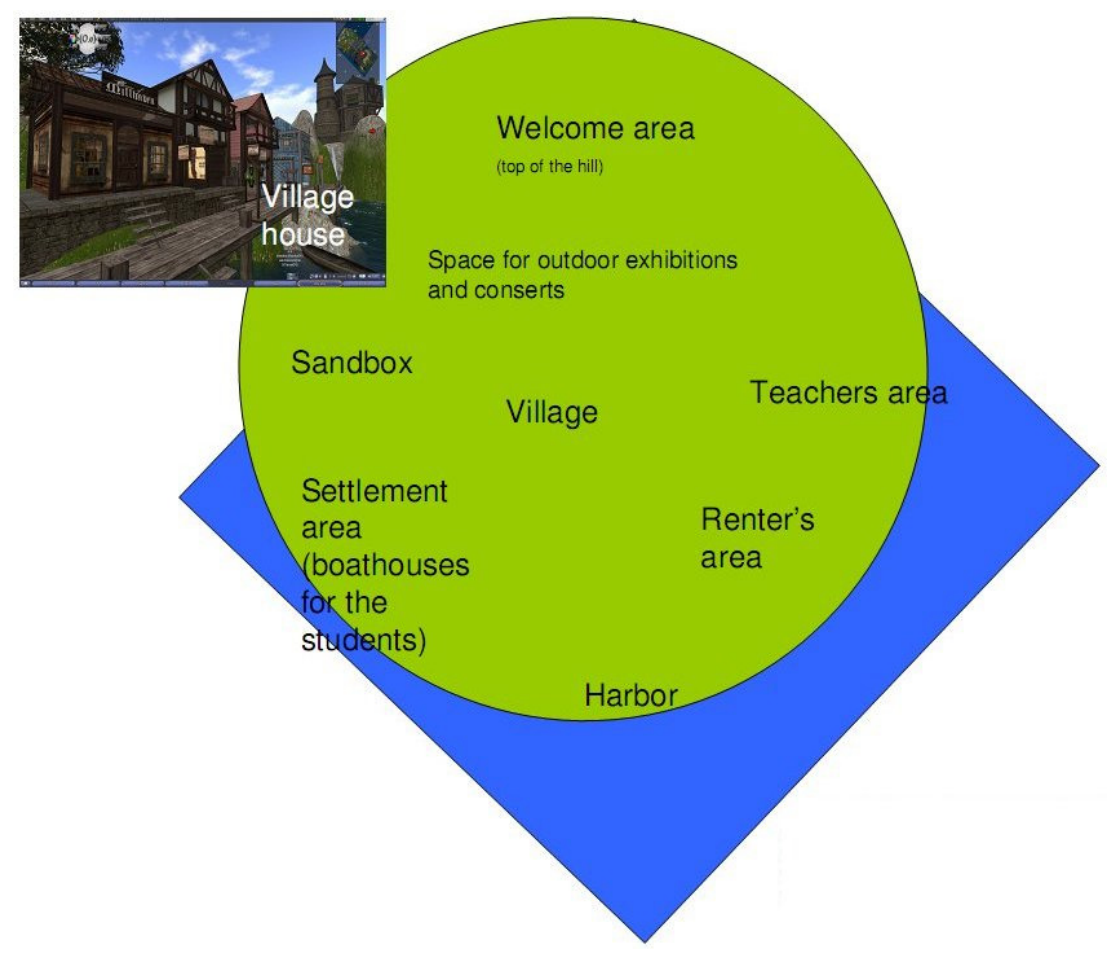
building rights on AVALON in a campus area. This will give them further opportunity to enhance their language skills through the development of everyday objects. 


\section{Facilities for learning on Avalon}

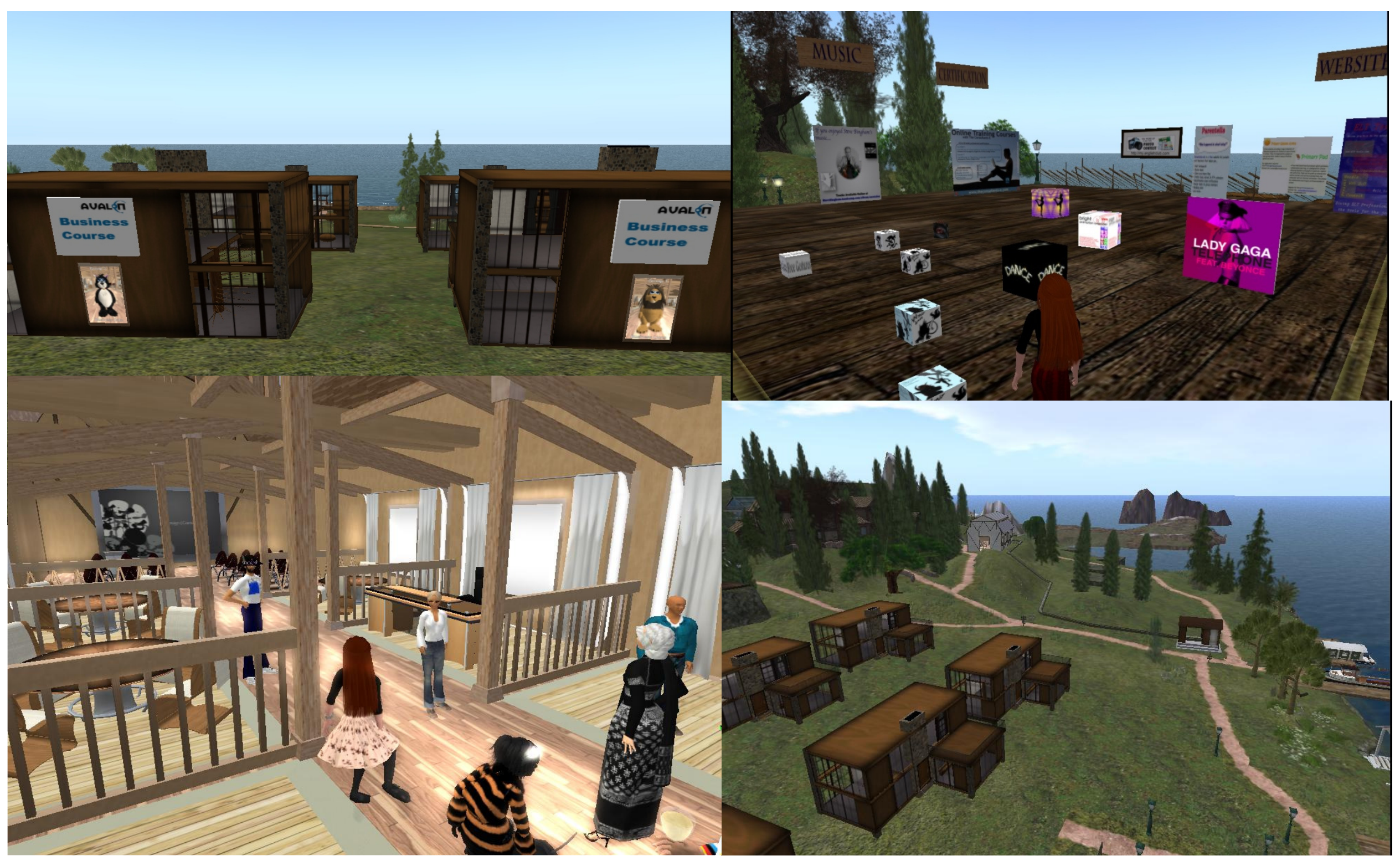




\section{DESIGN OF A REWARD MODEL}

\section{Outcome of discussion among educators}

- Possible tangible rewards: (1) free space on Avalon-island, (2) free language lessons, (3) Linden

dollars, and (4) Gold "avaloneuros" (an own currency that can be spent in 'the village', e.g. the pub or the store).

- Possible intangible rewards: (1) monument of honor in a 'hall of fame' or the village plaza or in front of the teaching location called the "business barn" and (2) upgrade in status/more permissions on Avalon-island.

\section{Outcome of Interview with} Students

- $\quad$ wins all the money that was collected during the Final Presentation (dragon's den)

- wins free support or consultancy by $<$ whom? >

- $\quad$ may stay in student quarter for another 6 months

- may advertise products in the village (free signpost)

- may set up a donation-box in the village

- entered into the 'role of honor' in the business barn

- may speak at an Avalon conference and advertise product/service

- wins a 'Stammtisch' (reserved table) in the pub 


\section{Specific Goals and Rewards calling on instrumental motivations}

Teacher's conclude to give the following rewards:

- successful completion of the course awarded title 'avalon entrepreneur' (new title, without extra rights)

- winner of business plan competition awarded 10 "avaloneuros"

- social award - a red Avalon-shirt

- technical award - a blue Avalonshirt

- language progress award (judged through self assessment and teacher assessment) - The students received a personalized certification that states achieved

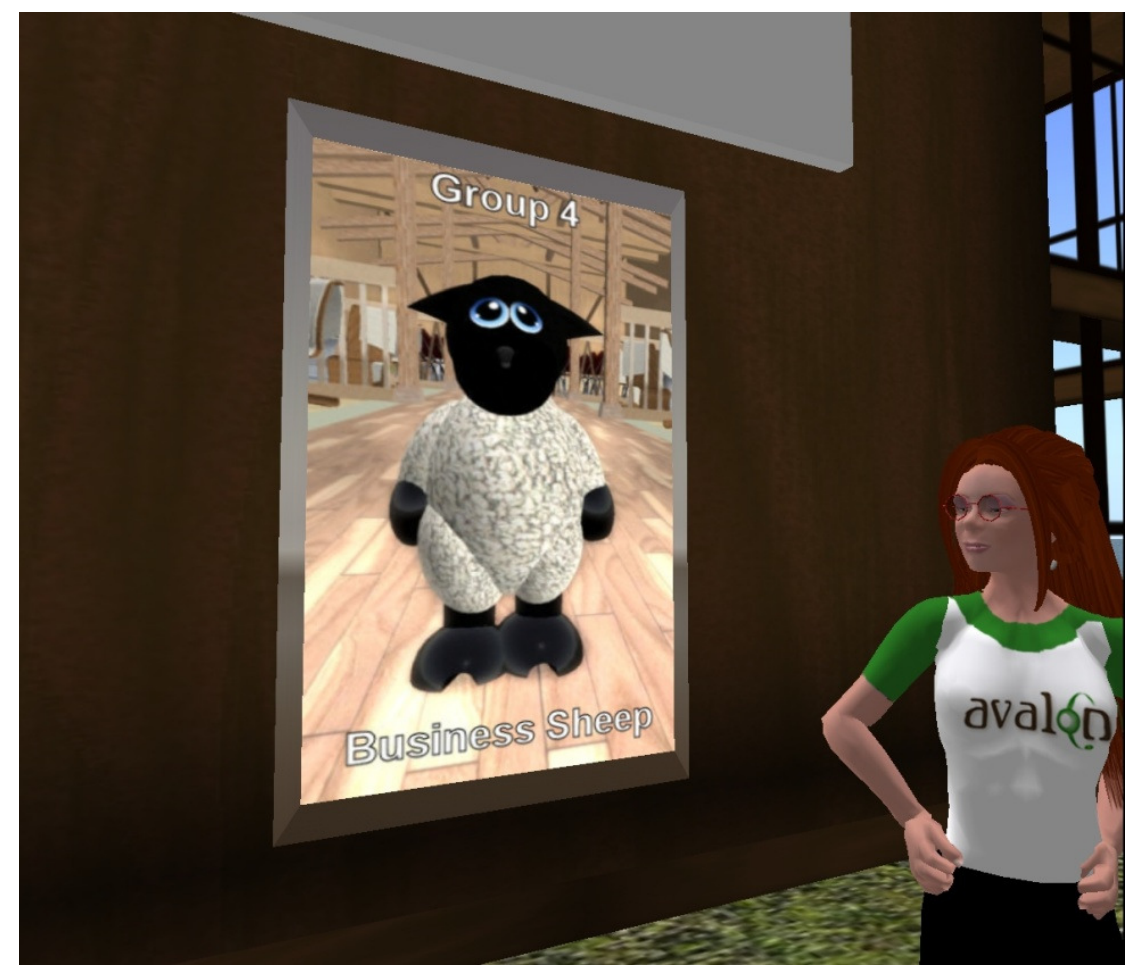
improvements. 


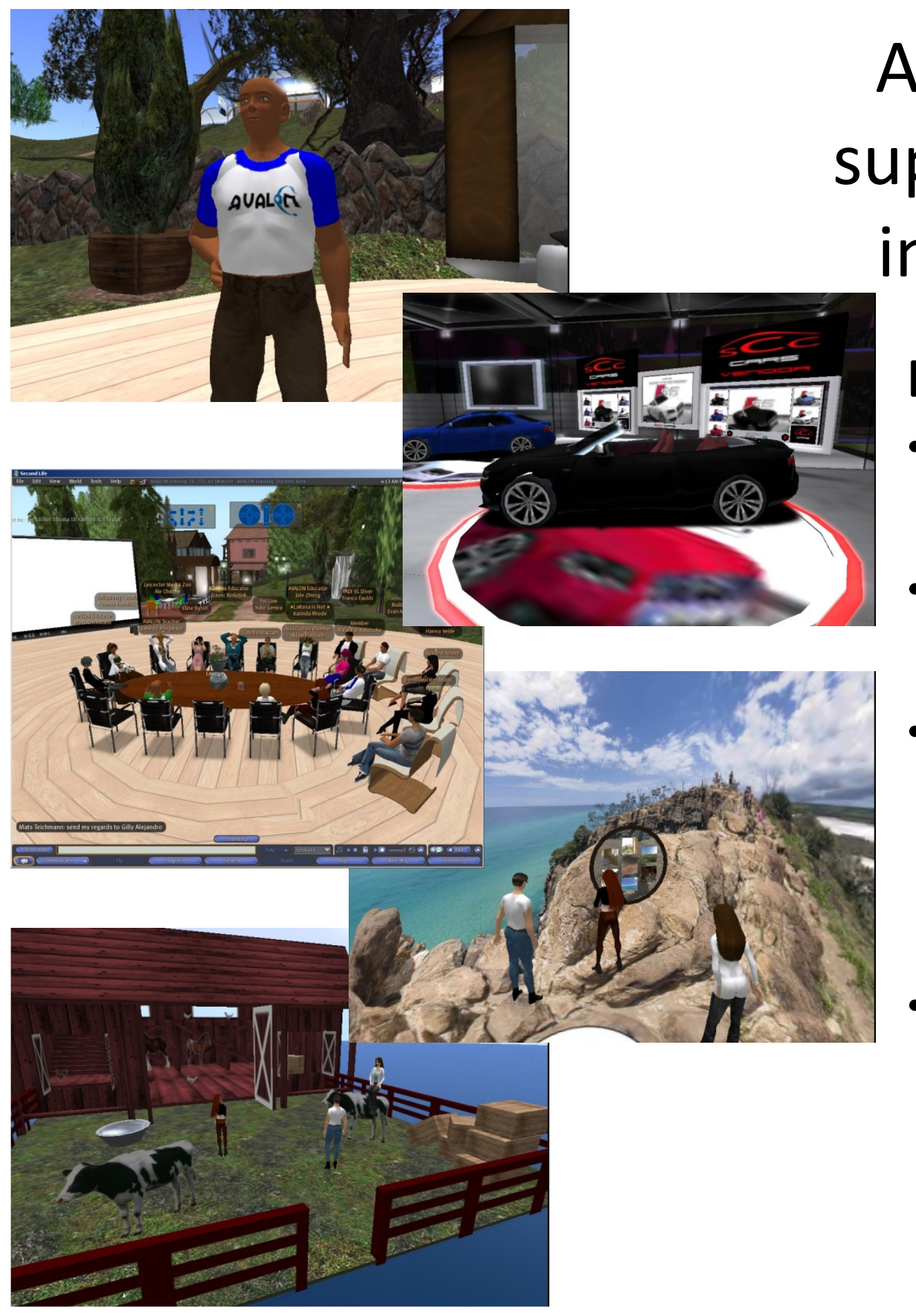

A reward model should support both intrinsic and integrative motivations

\section{Examples}

- Glory - having one's name added to a resource pool (to assist future new students).

- Sustenance - payment of Linden dollars or gifts of inventory for each activity, or level achieved.

- Access- invitations to seminars where the number of avatars are limited by virtual world resources; the creation of secret rooms that can be accessed only when a certain role is achieved.

- Facility - assignments to roles in a SL group with more abilities associated with increasing roles such as rights to create objects on parcels. 
In conclusion reward models should simulate the real-life nature of language learning where the ultimate reward of learning a language is the access to and full participation in its community.

Thank You

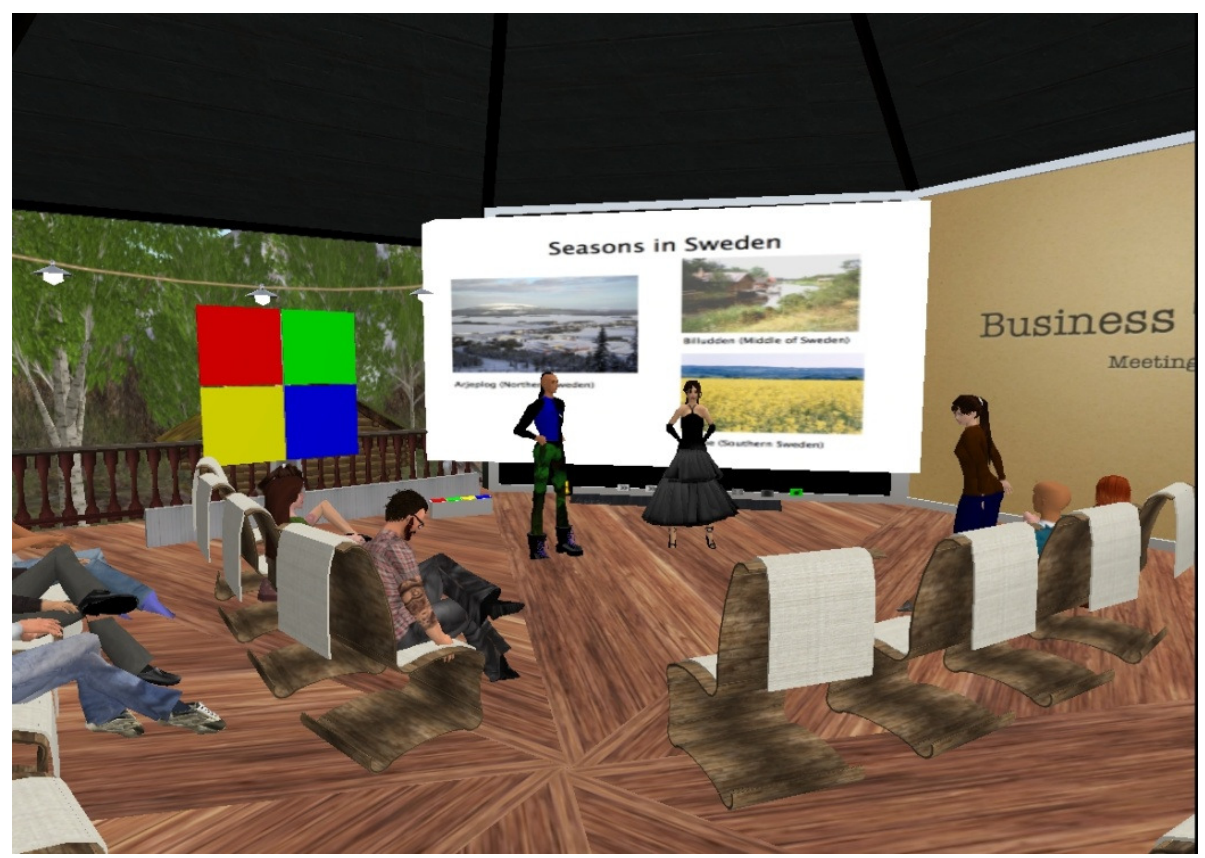
xiè xie

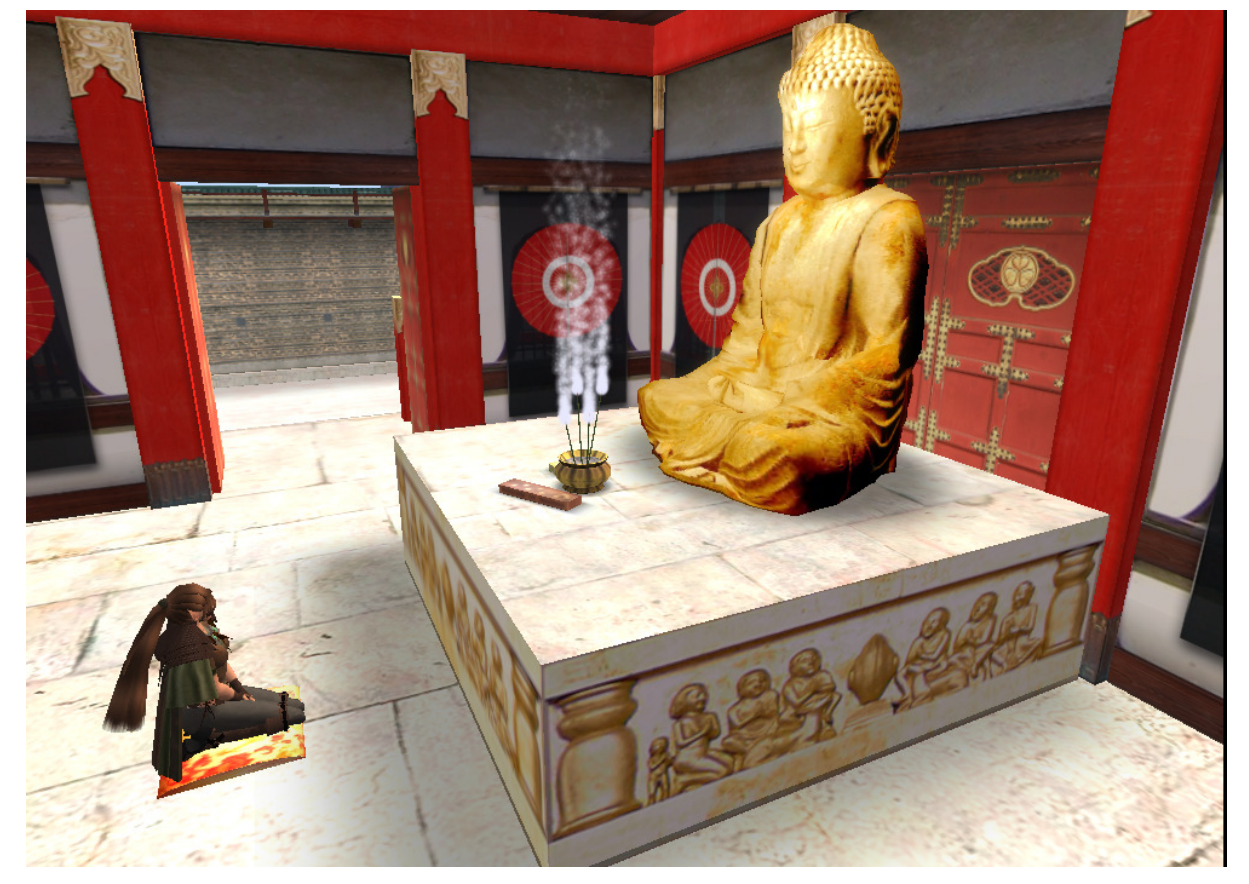




\section{References}

1. Crookall, David, and Rebecca L. Oxford. "Linking Language Learning and Simulation/Gaming.". In Crookall and Oxford, eds. eds. Simulation, Gaming, and Language Learning. New York: Newbury House Publishers, 1990. . (3-26)

2. Nardi, B., Ly, S., and Harris, J. (2007): Learning Conversations in World of Warcraft, In: Proceedings of HICSS 2007.

3. Carr, D. Oliver, M., Burn, A. (in press 2010): Learning, Teaching and Ambiguity in Virtual Worlds, In Peachey, A, Gillen, J, Livingstone, D, Smith-Robbins, S. (eds), Researching Learning in Virtual Worlds. UK: Springer.

4. Salen, K.and Zimmerman, E. (2004): Rules of Play. Cambridge, Mass., The MIT Press.

5. Salen, K.and Zimmerman, E. (2006): The game design reader : a Rules of play anthology, Cambridge, Mass., The MIT Press.

6. Oxford, R.L.\& Shearin, J.(1994). Language learning motivation: expanding the theoretical framework. Modern Language Journal, 78, 12-28.

7. Deci, E, L (1972). Intrinsic motivation, extrinsic reinforcement and inequity. Journal of Personality and Social Psychology, 22: 113-120, 1972.

8. Ushioda, E. (2001) Language learning at university: exploring the role of motivational thinking. In Z. Dörnyei \& R. Schmidt (Eds.) Motivation and Second Language Acquisition (pp.93-125). Honolulu, HI: University of Hawaii Press.

9. Syed, Z. (2001). Notions of self in foreign language learning: A qualitative analysis. In Z. Dörnyei \& R. Schmidt (Eds.), Motivation and second language acquisition (pp. 127-148). Honolulu, HI: University of Hawaii Press.

10. Wang, F. (2008) Motivation and English achievement: an exploratory and confirmatory factor analysis of a new measure for Chinese students of English learning. North American Journal of Psychology, December.

11. Deci, E., \& Ryan, R. (Eds.), (2002). Handbook of self-determination research. Rochester, NY:University of Rochester Press.

12. Deci, E., \& Ryan, R. (2008). Facilitating optimal motivation and psychological well-being across life's domains. Canadian Psychology, 49, 14-23.

13. Swan, R. H. (2008): Deriving Operational Principles for the Design of Engaging Learning Experiences, Dissertation, Brigham Young University, April 2008.

14. Crawford, C. (1984). The Art of Computer Game Design. Retrieved Jan. 2007, from http://www.vancouver.wsu.edu/fac/peabody/game-book/Coverpage.html.

15. Crawford, C. (2003). Chris Crawford on Game Design: Prentice Hall Ptr.

16. Csikszentmihalyi, M. (1990). Flow: The Psychology of Optimal Experience: Harper \& Row.

17. Rieber, L. P. (1996). Seriously considering play: Designing interactive learning environments based on the blending of microworlds, simulations, and games. Educational Technology Research \& Development, 44(2), 43-58.

18. Csikszentmihalyi, M. (2002). Mihalyi Csikszentmihalyi on Motivating People to Learn: George Lucas Educational Foundation.

19. Hallford, N., \& Hallford, J. (2001). Swords \& Circuitry: A Designer's Guide to Computer Role-Playing Games: Thomson Course Technology. 